\title{
latrogenic Obesity
}

National Cancer Institute

\section{Source}

National Cancer Institute. Iatrogenic Obesity. NCI Thesaurus. Code C120378.

Obesity resulting from medical treatment or intervention. 